\title{
Correction to: Process Driven Access Control and Authorization Approach
}

John Paul Kasse, Lai Xu, Paul de Vrieze and Yuewei Bai

\section{Correction to:}

Chapter "Process Driven Access Control and Authorization Approach" in: X.-S. Yang et al. (eds.), Fourth International Congress on Information and Communication Technology, Advances in Intelligent Systems and Computing 1041, https://doi.org/10.1007/978-981-15-0637-6_26

In the original version of the book, the author name has been updated from "Paul deVrieze" to "Paul de Vrieze" in the Chapter "Process Driven Access Control and Authorization Approach". The chapter and book have been updated with the changes. 